\title{
LexCult
}

| DEPOIMENTO

DOI: https://doi.org/10.30749/2594-8261.v3n1p41-47

\section{FÓRUM DE AUDIOVISUAL - CINEMA NACIONAL EM DISCUSSÃO NO CENTRO CULTURAL DA JUSTIÇA FEDERAL (CCJF), UM CASO DE SUCESSO}

\author{
Elaine Pauvolid Hamburger ${ }^{*}$
}

O Fórum de Audiovisual - Cinema Nacional em Discussão no CCJF foi um evento realizado pelo Centro Cultural Justiça Federal (CCJF) com apoio da Centro Técnico do Audiovisual (CTAv) e consultoria da pesquisadora Profa. Dra. Márcia Bessa ${ }^{1}$. Composto de mesas de comunicações selecionadas por chamada pública, mesas redondas com profissionais da área, debates, oficina e exibição de filmes, o evento ocorreu em 2018 na Sala de Sessões e no cinema do CCJF, com entrada franca.

A inciativa de realização do evento partiu de uma matéria de jornal que dava conta de que a maioria dos filmes brasileiros de médio orçamento, ainda que premiados internacionalmente, não conseguiam ficar tempo suficiente em cartaz, nem ocupar um grande circuito. A partir deste dado é fácil perceber que o espectador local tem pouquíssimo acesso ao que há de melhor no cinema nacional, sobretudo no seu viés mais artístico/autoral, questionador do ser social, constituidor de identidades, possuidor de inegável vocação para transmissão de saberes de extrema importância, principalmente num país às voltas com dificuldades cada vez maiores na educação tradicional.

A aproximação do público a profissionais, em um debate estrutural do cinema, nos pareceu ser o caminho para estimular o interesse pela cinematografia brasileira contemporânea e fornecer mais uma oportunidade para os profissionais discutirem tais temas. Daí surgiu a ideia do Fórum.

Vera Zaverucha, consultora e ex-diretora da ANCINE, Daniela Pfeiffer, à época Diretora do CTAv, Ilda Santiago, Diretora Executiva do Festival do Rio e a produtora Carla Sobrosa, entre outros parceiros do CCJF, apoiaram com dicas

\footnotetext{
* Responsável pelo Setor de Artes Cênicas e Audiovisual do CCJF.

${ }^{1}$ Pós-doutora pelo ECO/UFRJ e Docente pela ECDR/IBAv.
} 
generosas e entusiasmo desde a fase inicial do projeto, quando ainda se tratava de uma demanda institucional direcionada ao Setor de Artes Cênicas e Audiovisual deste Centro Cultural. De fato, a origem do Fórum de Audiovisual foi um pedido da Direção do CCJF para que fosse realizado um evento que fizesse justiça ao cinema brasileiro, que de certa forma "colocasse o CCJF à disposição do cinema".

Entendendo "fazer justiça ao cinema brasileiro" como o oferecimento do espaço para exibição e debate sobre o tema, visando à valorização e difusão dele, pode-se dizer que o evento, que veio a ser o Fórum de Audiovisual - Cinema Nacional em Discussão no Centro Cultural da Justiça Federal, além de cumprir seu objetivo, também se tornou um caso exemplar de atuação de agentes e instituições culturais em conjunto.

Com a tradição de cessão de espaços, mas sem muitas oportunidade de produzir nossos próprios seminários, nós, do Setor de Artes Cênicas e Audiovisual, nos unimos aos outros setores do CCJF e juntos começamos a pensar o projeto. A princípio com o setor de Contratos Culturais, capitaneado pela servidora e bacharel em Direito, Silvia Rachel e com a Diretora Executiva Maria Geralda de Miranda, que não só nos auxiliou no que foi necessário, mas também participou ativamente no recorte do projeto, emprestando sua experiência acadêmica e de organização de seminários, o que foi um grande diferencial. Da mesma forma, todos os outros setores do CCJF se envolveram ativamente, atuando em suas áreas, mas também participando da logística do evento. A coordenação das mesas de comunicações ficou a cargo do Me. Eduardo Barbuto Bicalho, que também é servidor do CCJF e EditorGerente da LexCult - Revista Eletrônica do CCJF.

Este espírito colaborativo e a coesão da equipe do CCJF já seria o motivo para chamar o evento um caso de sucesso, pois com o envolvimento de todos fomos capazes não só de realizar um fórum sobre cinema, mas de executá-lo a contento, oferecendo, além de palestras e exibição de uma mini mostra, espaço para comunicações de estudantes e pesquisadores e uma oficina de animação coordenada pelo CTAv, na pessoa do professor Sergio Arena. A elaboração das mesas redondas, definição dos temas, filmografia e coordenação da chamada pública para as comunicações contou com a consultoria da pesquisadora e Profa. ${ }^{\mathrm{a}} \mathrm{Dr}^{\mathrm{a}}$. Márcia Bessa. 
As mesas redondas discutiram o audiovisual brasileiro, com foco no cinema, mas especificamente o de pequeno e médio portes, realizado no período entre a pósretomada e a atualidade. Estabeleceu-se um panorama crítico do cinema nacional contemporâneo, com foco nas estratégias de alcance de público.

Falou-se também sobre políticas públicas de incentivo, iniciativas independentes, tanto no que se refere ao conteúdo quanto ao que se relaciona com a exibição, a distribuição e a publicidade. Também esteve em pauta a dinâmica do incremento cada vez maior das novas tecnologias audiovisuais, como TVs por assinatura e VOD (video on demand) e a relação como o cinema, bem como as propostas inovadoras que tentam diminuir a evasão das salas de cinema, seja pelo valor monetário dos ingressos, seja por dificuldades de distribuição das produtoras e as facilidades do streaming.

As mesas redondas compuseram-se de diretores, produtores, roteiristas, exibidores, estudiosos do audiovisual e gestores culturais. Os temas norteadores dos debates foram o balanço geral do audiovisual nacional atual; exibição cinematográfica, espectatorialidade, hábitos de consumo cinematográfico, impacto das novas tecnologias audiovisuais e hábito de ir ao cinema; disseminação dos festivais, mostras de cinema e audiovisual e a contribuição dos avanços tecnológicos para esse cenário.

Os trabalhos apresentados nas mesas de comunicações, que foram aprovados pelo Comitê Editorial do periódico, estão publicados nesta edição da Revista LexCult, como forma de manter o debate vivo e talvez oportunizar a realização de um segundo fórum.

Nossa intenção, a princípio, era montar no mínimo duas mesas compostas por representantes de órgãos públicos importantes para cinematografia nacional e festivais de cinema e, ao menos, um produtor/roteirista/diretor de alguns dos filmes premiados nos últimos festivais cinemas, bem como estudiosos com foco no cinema contemporâneo. Conseguimos montar três dias de seminário, com duas mesas em cada dia.

Participaram do evento a Diretora Executiva do Festival do Rio, Ilda Santiago, a Diretora do CTAv, Daniela Pfeiffer, o exibidor do Cine Joia, Rafael Aguinaga, e ainda Flavio Ramos Tambellini, diretor que nos possibilitou a exibição do seu filme A Gloria e a Graça na Mini-Mostra Fórum de Cinema Brasileiro Contemporâneo, na qual 
também foram exibidos o curta Conto de Fadas (14min, Brasil, 2017, Caio Scott), Aquilo que Sobra (77min, Brasil, 2018, Humberto Giancristofaro) e o "Especial Canal O Cubo", que consiste na seleção dos filmes premiados na última edição do $5^{\circ}$ Festival 0 Cubo de Cinema, organizado por Tiago Fraga, que também participou das mesas de debates.

Tivemos ainda a presença dos estudiosos Prof ${ }^{\circ}$. Dr. João Luiz Vieira e Profo. Dr. Wilson Figueiredo; o Diretor de Conservação da Cinemateca do MAM, Hernani Heffner; os Diretores Luis Carlos Lacerda (o Bigode) e Tizuka Yamasaki, dentre outros convidados. Para ter acesso à programação completa do evento ainda é possível acessar a programação no site do CCJF.

Ainda que a proposta tenha sido a realização de um evento para o público em geral e não apenas para profissionais da área, a parceria como o CTAv nos possibilitou abrigar uma oficina de animação, cujas vagas se esgotaram tão logo abriram. Isso nos mostrou que o público não se interessa apenas pelo conteúdo exibido, mas também pela feitura do cinema.

Acreditamos que o Fórum de Audiovisual - Cinema Nacional em Discussão no CCJF respondeu ao contexto da produção audiovisual comercial e autoral brasileira, que vivia uma fase de vigor, tanto em termos de qualidade e conteúdo quanto de técnica, sem, no entanto, se favorecer de uma distribuição que esteja à altura.

Depois de tudo que aprendemos no evento, lançamos algumas questões que poderiam ser debatidas em um eventual segundo Fórum: Walter Benjamim, em A obra de arte na era de sua reprodutibilidade técnica, sustenta que o cinema não apenas possibilita a difusão massiva das obras, mas força-a, ou seja, que o alto custo de produção de um filme exige a sua distribuição em larga escala. Considerando essa afirmativa, poderíamos dizer que essa realidade estaria se modificando em razão dos novos dispositivos móveis disponíveis, uma vez que seriam outras formas de distribuição que não as das salas de exibição? Não entramos na era do cinema na palma da mão?

Ou, pelo contrário, a experiência do cinema em salas de exibição seria em si um espetáculo único, incapaz de ser reproduzido pelos novos dispositivos tecnológicos? Cinema em si, não seria um evento social por excelência, muito além 
EM DISCUSSÃO NO CCJF...

de ser apenas uma linguagem audiovisual? A tecnologia não poderia ajudar a quebrar barreiras na experiência do cinema ao invés de esvaziar os espaços coletivos e isolar os homens em seus dispositivos móveis de última geração?

Encerremos com as palavras de Walter Benjamin e deixemos estas questões para uma próximo encontro:

A reprodutibilidade técnica do filme funda-se imediatamente sobre a técnica de sua produção. Esta não somente possibilita do modo mais imediato a difusão massiva das obras cinematográficas, mas força-a. Ela a força pois a produção de um filme é tão cara que um indivíduo o qual poderia, por exemplo, pagar por um quadro - não pode mais pagar por um filme. [A: "O filme é propriedade do coletivo."] Em 1927 calculou-se que um filme maior, para que fosse rentável, devia alcançar um público de 9 milhões. Com o cinema falado, aliás, introduziu-se em seguida inicialmente um movimento regressivo; seu público limitou-se por barreiras linguísticas (BENJAMIN, 2015).

\section{REFERÊNCIAS}

BENJAMIM, Walter. A era da reprodutibilidade Técnica. 2015. Organização e a apresentação Marcio Seligmann-Silva, tradução Gabriel Valladão Silva. Versão Kindle. Posição 1266. 

EM DISCUSSÃO NO CCJF...

\section{ANEXO I - FOTOS DO EVENTO}

\section{Imagem 1 - Fórum de Audiovisual - Mesa Redonda}

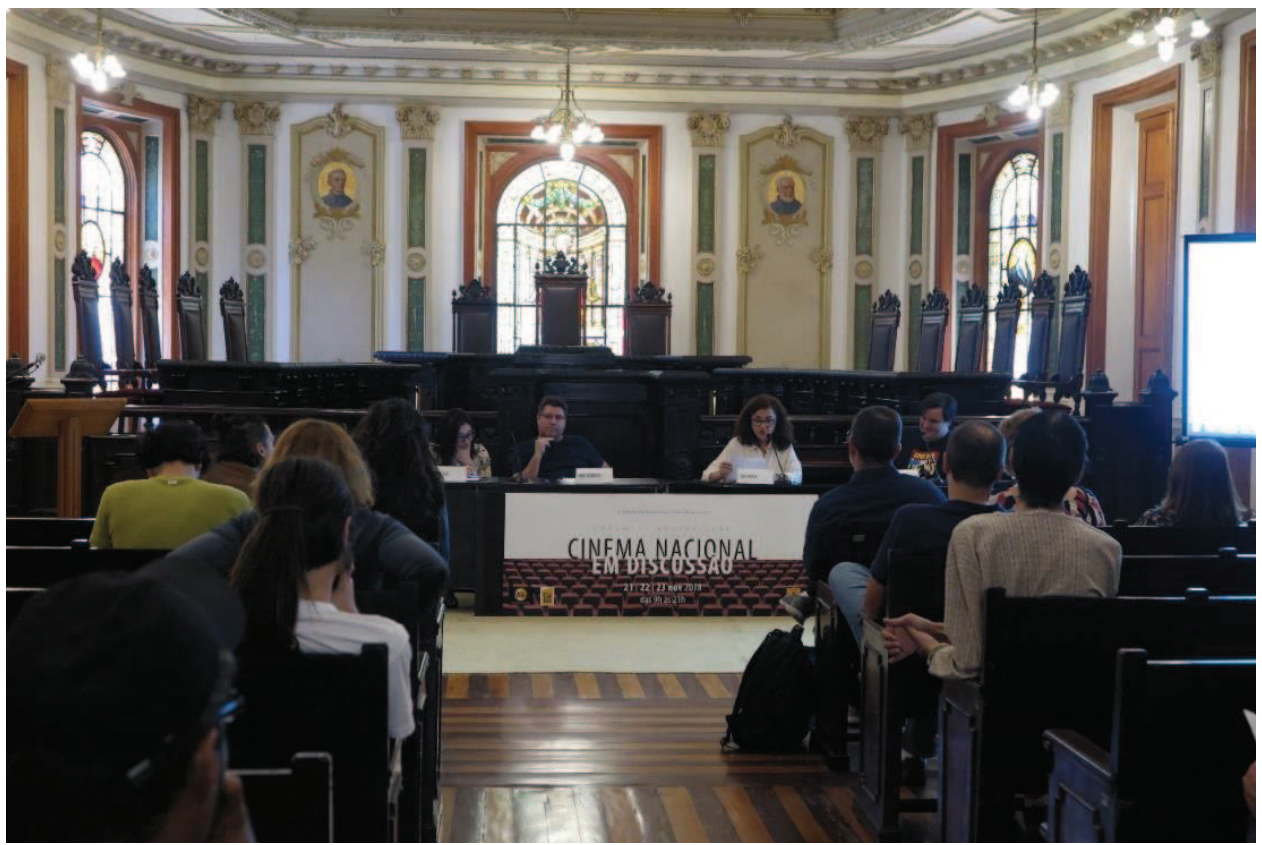

Fonte: Setor de Comunicação Institucional do CCJF

\section{Imagem 2 - Fórum de Audiovisual - Mesa Redonda}

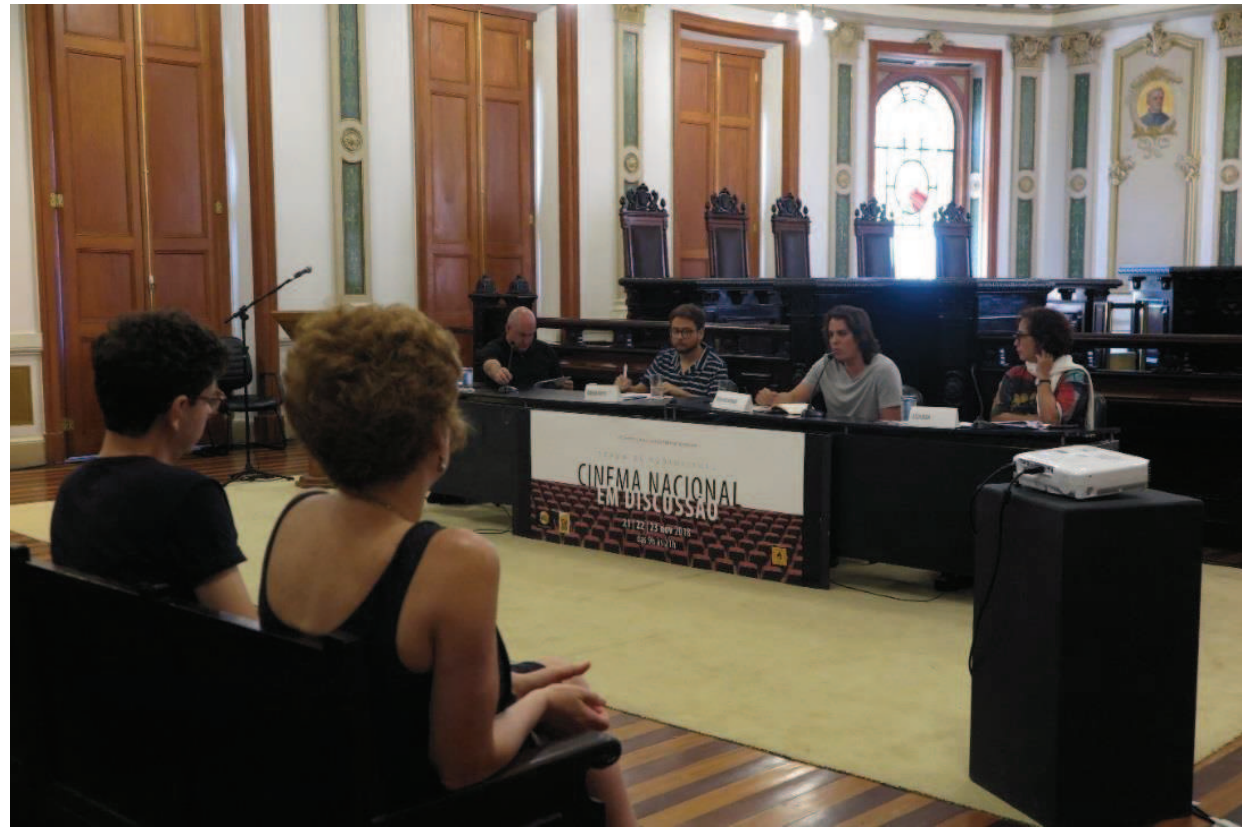

Fonte: Setor de Comunicação Institucional do CCJF 

EM DISCUSSÃO NO CCJF...

\section{Imagem 3 - Fórum de Audiovisual - Mesa Redonda}

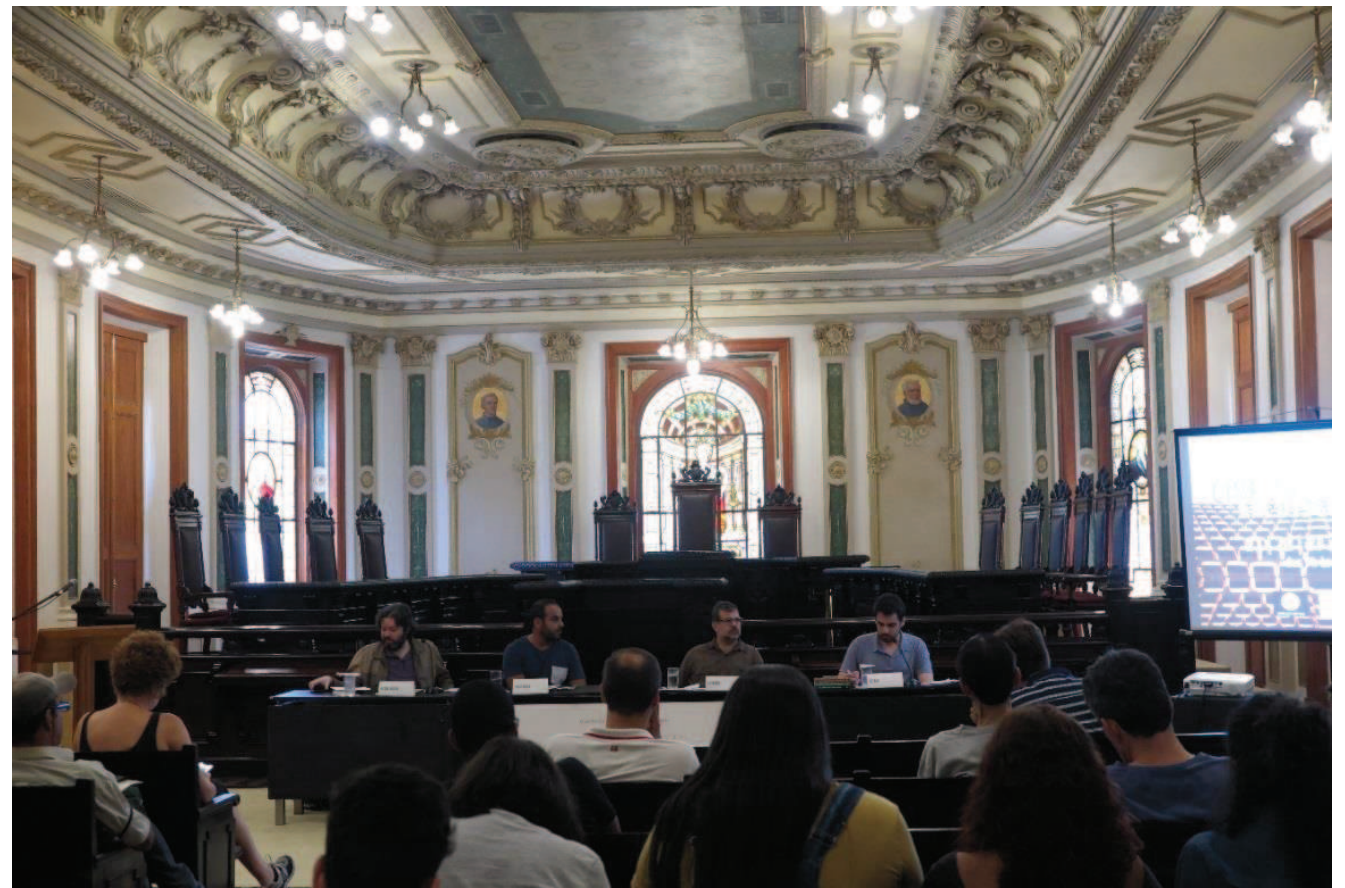

Fonte: Setor de Comunicação Institucional do CCJF 